\title{
DEL SÍMBOLO A LA METONIMIA VÍA KAFKA. MUNDO ANIMAL DE ANTONIO DI BENEDETTO
}

\author{
FROM SYMBOL TO METONYMY THROUGH KAFKA: \\ MUNDO ANIMAL BY ANTONIO DI BENEDETTO

\section{Rafael Arce} \\ Universidad Nacional del Litoral, Consejo Nacional de Investigaciones \\ Científicas y Técnicas. Santa Fe, Argentina. \\ rafael.arce@gmail.com
}

\begin{abstract}
Resumen: El trabajo propone una lectura de Mundo animal (1953) de Antonio Di Benedetto en relación con los relatos de animal de Franz Kafka. La lectura sigue en gran parte la línea interpretativa que Deleuze-Guattari han abierto en la obra del escritor checo. El animal en Di Benedetto ha sido leído de modo predominante como metáfora de lo humano. Su simbolismo, como sentido que trasciende la fábula, la alegoría y el fantástico, ha obturado la posibilidad de una lectura no-metafórica: considerar el devenir animal del hombre y el devenir hombre del animal. Este trabajo propone una clave de lectura que restituye a los cuentos de Mundo animal el movimiento de su imaginación: el que descompone el juego metafórico en una dinámica metonímica que vuelve lo animal un rasgo literal de lo humano.
\end{abstract}

Palabras clave: Animal, Kafka, metonimia, imaginación, devenir.

\begin{abstract}
This paper proposes a reading of Mundo Animal by Antonio Di Benedetto regarding animal stories of Franz Kafka. This reading mostly follows the interpretative line that Deleuze-Guattari have opened in the work of the Czech writer. The animal in Di Benedetto has predominantly been read as a metaphor for the human. Its symbolism, as a sense that goes beyond the fable, allegory and fantasy, has blocked the possibility of a non-metaphoric reading: to consider the animal becoming man and the man becoming an animal. This paper proposes a reading that restores the movement of imagination to the tales of Mundo animal: the one that breaks down the metaphorical game into a metonymic dynamic that makes the animal a literal feature of the human.
\end{abstract}

Keywords: Animal, Kafka, metonymy, imagination, becoming.

Recibido: 04.10.2015. Aceptado: 29.01.2016. 


\section{$\mathrm{E}$} N EL AÑo 2006, Adriana Hidalgo editó los Cuentos Completos de Antonio Di Benedetto. El tomo vino a coronar la sistemática operación de rescate que la labor editorial, junto con la filológica y la crítica, viene realizando con la obra del escritor argentino desde hace por lo menos dos décadas. El tomo se abre con una introducción escrita por Julio Premat, titulada "Lo breve, lo extraño, lo ajeno", en la cual se incorpora a la lectura las circunstancias filológicas de la edición. Estas circunstancias recogen, además, la historia de los avatares editoriales de los cuentos a lo largo de la vida del escritor mendocino: olvidos, reediciones, correcciones, cambios y omisiones. El análisis de esas peripecias es sugestivo y revelador: Premat lo vincula con el proyecto narrativo, poniendo en evidencia los componentes propiamente poéticos que los avatares de circulación y recepción contribuyen a considerar como constitutivos de la ficción, es decir, como inmanentes al despliegue de la obra y no solo como contingencias del contexto. La consideración de la vida del escritor (una existencia signada por lo funesto, lo aciago y lo trágico) se pone en correlación con su universo novelesco y, en este sentido, las circunstancias desafortunadas de su recepción crítica operan como gozne entre "vida" y "obra".

Esta articulación crítica vuelve predominante un tipo de lectura negativa de la narrativa dibenedettiana. Aunque estas lecturas sean diversas, el entramado escritor maldito -obra maldita- es el espectro común en el que se mueven en general las interpretaciones. Si tomamos Mundo animal (1953), su primer libro de cuentos, podemos resumir algunas de estas líneas múltiples: 1) La relación (problemática) con la fábula y el apólogo, lo que implica la "superación" de las ideas morales formuladas en el texto (Boldori, 1968; Maturo, 1987; Castellino, 1995); 2) La relación (también problemática) con el fantástico, que articula el pasaje de lo animal a lo humano y viceversa (De Miguel, 1970; Néspolo 2004; Premat, 2009); 3) El animal como instancia de producción simbólica (en sus diversas claves: jungiana, freudiana, autorreferencial') (Filer, 1980; Campos, 1987; Varela,

\footnotetext{
${ }^{1}$ Es decir, como simbología con significación propia al interior de la obra: "Con significaciones simbólicas y funciones diversas, el mundo animal está presente en la mayor parte de sus novelas y relatos breves, configurando así una suerte de simbología personal cuyo sentido, intrínseco a la obra pero también en relación con la cultura universal, puede aún ser profundizado desde diversos ángulos" (Varela, 2011, p. 280).
} 
2011); 4) Lo animal como interrogación de lo instintivo e irracional, como perspectiva de una vida no humana y su relación con la corporalidad (Premat, 2009; Varela, 2007).

Nosotros propondremos otra clave de lectura que, sin ser novedosa, no ha sido trabajada de manera sistemática. Muchos de los textos críticos, en cualquiera de estas líneas, mencionan la relación de Mundo animal con Kafka (Varela, 2007, p. 211; Yelin, 2010). Esta relación, evidente, no ha sido sin embargo desentrañada hasta sus últimas consecuencias. Sin embargo, una lectura que analice la relación de Mundo animal con Kafka podrá rehacer el camino desde la profundidad simbólica y la sofisticación interpretativa hasta el sentido más superficial del texto. Así trabajaron Marthe Robert (1963) y Gilles Deleuze y Félix Guattari (1978) con Kafka: des-sedimentando las capas de significación, de simbología, que habían saturado el texto, volviendo a una suerte de grado cero. En esta sustracción de sentido, los cuentos de animal kafkianos se acercan, de nuevo, a la fábula, sin confundirse con ella. Con Di Benedetto se puede proceder del mismo modo: en esa ingenuidad del escritor al llamarlos "fábulas" (la crítica se muestra presurosa por "superar" esa lectura inocente ${ }^{2}$ ) ¿no se encierra un sentido literal que, quizás, está más cerca de Kafka, es decir, de un animal no simbólico, que de la sofisticación de las lecturas más extendidas sobre su significado?

Los cuentos de Mundo animal están narrados en primera persona (esta modalidad es, por lo demás, predominante en toda la obra narrativa del autor). El volumen se abre con un texto breve, "Mariposas de Koch". El narrador da una explicación maravillosa de lo que, para el punto de vista de los otros (“dicen", “decís”, etc.), aparece como un fenómeno verosímil: el protagonista escupe cuajarones de sangre. Quien narra es un cuerpo enfermo, que traduce su mal físico en una extraña fábula: un día decidió comer margaritas, imitando a su burro, y casi por casualidad se comió una mariposa blanca. Después se comió otras dos: del estómago, la pareja de mariposas (pues una de las tres murió) pasó al corazón y ahí, una vez que

2 "Hay sin duda en este volumen una tendencia a lo alegórico con sutiles proyecciones hacia lo folklórico maravilloso que se prolonga en cierto didactismo no del todo velado en algunos textos. (...) Sin embargo, esas explicitaciones son límites o cercos arbitrarios que los propios relatos se encargan de sobrepasar" (Néspolo, 2004, p. 46). 
tuvieron descendencia, empezaron a querer salir del cuerpo. Lo hicieron por la boca, manchadas de sangre del corazón, y si no vuelan y caen al suelo es porque, criadas en la oscuridad, son ciegas (43-44). La vacilación propia del fantástico (Todorov, 1994, p. 38-39) está perfectamente marcada: lo anómalo (escupir sangre) admite dos explicaciones, una realista (la enfermedad) y otra maravillosa (la de las mariposas). Esta vacilación confronta dos puntos de vista: el del narrador y el de los otros o, también, el subjetivo y el objetivo ${ }^{3}$.

Esta estructura del fantástico es desbordada en la medida en que, entendemos, en el mundo narrativo de Di Benedetto no es posible sostener una oposición simple real/imaginario en la cual el segundo término aparezca como un onirismo o delirio compensatorio. Es una lectura predominante: la experiencia negativa, trágica, angustiante, de la realidad, su pobreza (material, social, existencial), ocasionan en el personaje de este universo una actividad imaginaria compensatoria (Varela, 2007, p. 215). Contra este tipo de lectura, se nos impone un doble movimiento suplementario: por un lado, desbordar la dicotomía que opone real a imaginario, tratando de considerar el modo de aparición de las cosas para una conciencia que se deshace de los compartimentos estancos que clasifican el orden de los fenómenos; por el otro, interpretar ese modo de aparición en términos no de carencia sino de potencia, de afirmación del poder de intensificación de la experiencia de un sujeto que se constituye en la imaginación como facultad de apertura de la realidad y no como su evasión.

En "Mariposas de Koch", la presumible tuberculosis alude de modo ostensible a la enfermedad de Kafka. Lo que el narrador percibe como manducación de las mariposas localiza la somatización de lo exterior en un continuo que va de la boca al estómago pasando por la garganta y el aparato fonador: casi todos los relatos de este libro harán intervenir de un modo u otro esa zona del cuerpo, la que posibilita la voz, la articulación y el lenguaje (Deleuze y Guattari, 1978, p. 33). A su vez, el tema de la tos, la boca, la garganta y el pecho, implican, como en Kafka, la figuración de lo animal. Veremos que esta percepción desaforada del aparato fonador vincula arti-

3 “Lo fantástico surgirá de la confrontación entre una lógica que el sujeto pretende real y un universo que escapa a las leyes del realismo y lo enfrenta consigo mismo, con su propia animalidad" (Néspolo, 2004, p. 51). 
culación verbal, sonido inarticulado, musicalidad, a-musicalidad, canto y voz animal, y tiene un correlato en la dicción de la prosa dibenedettiana.

Ahora bien, también es común en la crítica de Mundo animal hacer recaer el análisis en la historia narrada, sin que parezca relevante considerar el modo y el ritmo de la prosa. Esta reducción convive con las consideraciones sobre el estilo de Di Benedetto (su musicalidad, su rareza, su pudor o laconismo, su minimalismo), pero las dos no siempre se articulan ${ }^{4}$. Esta omisión implica la cuestión de lo simbólico y lo alegórico, que a nosotros nos gustaría plantear, siguiendo a Deleuze y Guattari, como el problema más general de lo metafórico. Una vez asumido que el animal no es maravilloso ni realista sino simbólico, no importa el nivel de refinamiento en la lectura, ni el código en el que se interprete: todo símbolo implica una concepción metafórica del animal (Néspolo, 2004, pp. 52-53), lo que arrastra una metafísica. Nosotros creemos que el animal dibenedettiano es un devenir. Esto parece una mera traslación de la lectura que hacen Deleuze y Guattari de Kafka (algo de lo que no renegamos: en cierto modo, Di Benedetto potencia una figuración que está ya en el escritor checo), pero en Mundo animal tiene una modulación particular que implica, precisamente, la imagen verbal (y no, como parece desprenderse de las lecturas que se conforman solo con la historia, la imagen visual) ${ }^{5}$.

Analicemos el problema en otro relato, "Nido en los huesos". Tiene dos partes: en la primera, el padre del narrador adopta un mono que, al no poder integrarse a la familia, es relegado a una palmera. Se vuelve arisco y experimenta la severidad del jefe de hogar. Finalmente, éste manda tumbar la palmera y el animal, sin refugio, es despezado por los perros. La segunda parece una derivación de la identificación del narrador con el mono: él también sufre la severidad del padre. Por supuesto, ya estamos de nuevo en Kafka: la autoridad paterna, la humillación, el sentirse un animal (el cuento

${ }^{4}$ Hay notables excepciones, aunque la interpretación de la articulación difiera de la nuestra (Premat, 2009, pp. 11-14).

5 "Como en los relatos de Kafka -aunque en Di Benedetto de un modo más lineal y previsible-, hay una tensión continua entre la parábola y el sentido más lato de las expresiones, un juego que es especialmente productivo cuando se trata de imaginarios de animales, cargados de un pesado lastre simbólico" (Yelin, 2010, p. 267). Para nosotros, ese "modo más lineal y previsible" tiene que ver simplemente con que estos relatos de Di Benedetto han procesado ya el estatuto del animal kafkiano. 
comienza: "Yo no soy el mono", 49). No sabemos si el mono es un rodeo metafórico para hablar de una infancia traumática o si su historia es literal y proyecta (anticipa o produce) la del narrador. En la segunda parte, el protagonista decide convertir su cabeza en hogar de pájaros, como una especie de compensación hacia los animales después de la muerte del mono: decide, entonces, "adoptar" sus propios "pichones". Otra vez se admite la lectura del fantástico: la madre lo reta porque, cuando está tomando el té con sus amigas, el niño entra en la sala silbando, lo que en su punto de vista es el canto de los pájaros (50), mientras que, cuando son los buitres los que se apoderan del nido, y los picotazos lo hacen estremecerse de dolor, puede interpretarse que el narrador lo fabula para explicar lo que no sería más que otra enfermedad: la migraña (51).

Tenemos todos los elementos del animal simbólico-edípico, que además se reapropia del mismo tratamiento kafkiano: la inadaptación al entorno familiar (las mariposas del otro cuento también "anidaban y hacían familia”), el animal sacrificado, la interiorización de la culpa (el narrador se convierte en "padre" y "nido" de los pájaros, es decir, de seres que quieren volar, ser libres, despegarse), la corrosión final de esa culpa interiorizada, el fracaso y el deseo de repetir el aciago destino del mono. Sin embargo, una frase del texto obliga a una reconsideración de la fábula que incorpore la imaginación verbal:

Con el cambio he dudado un tanto de que haciendo la felicidad de un pájaro haré la felicidad de todas las familias de los siglos venideros. Si todos pusiéramos nuestra cabeza al servicio de la felicidad general, tal vez podría ser. Pero nuestra cabeza, no sólo el sentimiento (51).

El fragmento constituye un núcleo que puede encontrarse en todos los cuentos: una reflexión moral, una enseñanza al modo de la fábula. Lo explícito de la idea moralizante es, en principio, contrario a la extrañeza y ambigüedad características de este narrador: puede incomodar al lector como algo demasiado evidente en un texto más bien oscuro. Los críticos tratan de salvar rápidamente esta incomodidad atendiendo al modo en el que el texto trasciende esa exposición de ideas antipática a su polivalencia de sentidos ${ }^{6}$.

6 "La denominación de 'fábulas' entonces, como el mismo autor llama a estos cuentos, no resulta suficiente para categorizarlos” (Néspolo, 2004, p. 47). 
Nosotros proponemos otra hipótesis. Cada cuento es un experimento narrativo que parte de una frase hecha: la moraleja de la fábula o la enseñanza de la alegoría. El pivote del relato está en ese núcleo verbal, que se expresa en forma de lugar común moralizante: a partir de ese núcleo, cada narrador fabula su historia. ¿De qué modo? La idea moral es netamente metafórica: "poner la cabeza al servicio de la felicidad" es la expresión de una enseñanza que se articula figurativamente. El cuento se desprende de una metamorfosis: realiza la frase volviéndola literal'. Se trata del procedimiento de verosimilización. "Cabeza" es la palabra clave, porque remite al cuerpo. Lo metafórico de la enseñanza se vuelve literal: la verosimilización consiste en escribir una ficción en la cual la frase "se explique" a través de la historia. El proceso arrastra todas las metáforas, que son destruidas en el devenir: el "nido", metafóricamente "la familia" (símbolo edípico), se vuelve un nido real. La elección del pájaro se desprende de la palabra "nido" y no al revés. El mono no se integra a la familia. El narrador, identificado, trata de "criar" una propia. Al poner la cabeza al servicio de una armonía familiar imposible, el "hogar" se transforma en "nido" y el nido, literalmente, atrae bandadas, múltiples de pájaros. El "criar", de nuevo (criar un hijo, criar animales, criar pájaros), atrapado por la frase hecha, genera el desenlace del cuento: "buitre" es el que consume despiadadamente sin retribución, el ave carroñera, como el hijo desagradecido. Resto de metáfora: el narrador paga con la agonía su deseo final de destruir el hogar familiar, de aniquilar el nido.

"Mariposas de Koch" se puede leer del mismo modo. No es tan fácil en este caso, pero puede hacerse si se repone una laguna en el relato: el narrador estaría enamorado. No es una reposición forzada, porque el tema del amor, la pareja, el erotismo, atraviesa toda la obra de Di Benedetto. Además, la historia de "la pareja de mariposas", el rojo de la sangre, el corazón, etc., pueden estar figurando una historia de amor trágica (como la de otro cuento del volumen, "Las poderosas improbabilidades"). En el imaginario amoroso de esta obra, siempre la pareja está interferida por un tercero

${ }_{7}^{7}$ Yelin subraya la importancia de este procedimiento, aunque ella no se refiere al lugar común verbal como expresión de una máxima moral: “En 'Nido en los huesos', el narrador se propone poner la cabeza al servicio de la felicidad general, llenándola de pájaros. La imagen 'tener pajaritos en la cabeza' se convierte rápidamente en una descripción objetiva y siniestra" (Yelin, 2010, p. 267). Volveremos sobre su lectura, que tiene muchos puntos en común con la nuestra. 
(sirva de ejemplo el mismo cuento, pero también las novelas El pentágono y Zama). Un lugar común pretende que el enamoramiento puede describirse como "sentir mariposas en el estómago". Este es el punto de partida: el narrador toma literalmente la idea y la "verosimiliza", es decir, fabula un relato que la pueda explicar y contener. El proceso implica de nuevo la metafórica familiar-edípica: la pareja se traslada del estómago al corazón. El cuerpo del narrador pasa, entonces, de las mariposas en el estómago a la estabilización del amor de pareja en el "hogar": "Se trasladaron al corazón, más reducido, quizás, pero con las comodidades de un hogar moderno, por lo que está dividido en cuatro departamentos o habitaciones, si así se prefiere nombrarlos" (44). Después, viene la descendencia y la necesidad de los hijos de "volar". El amor romántico, convertido en familiar, termina en el desgarramiento y la enfermedad: el "estrellarse" de los hijos contra el "suelo", el querer volar y terminar, "por ceguera", dando por tierra las aspiraciones de ascenso, es de nuevo un lugar común social que se vuelve literal.

La sobriedad del estilo dibenedettiano, muy señalada por la crítica, pero poco articulada en Mundo animal con la ficción que tramita con la fábula, puede ser pensada como sustracción de rasgos estilísticos literarios del mismo modo que Deleuze y Guattari lo piensan con el alemán de Kafka: una extenuación del estilo cuya potencia se genera por minimización, por golpes de austeridad dados a la lengua mayor (Deleuze y Guattari, 1978, pp. 35-39). La sobriedad alcanza ese lugar común de la moraleja, pero esa moraleja se transforma volviendo la metáfora moral una fábula humana, $o$ una parábola, que se destruye a sí misma en el proceso de su verosimilización. Mundo animal es una máquina anti-metafórica ${ }^{8}$, metonímica, catacrética: toma la vertical del sentido (del símbolo) y opera transmutándola (la metamorfosis de la imaginación verbal es correlativa de los procesos de metamorfosis animal-humano y humano-animal) en la horizontal del funcionamiento. ¿Por qué hablamos de catacresis? Recordemos que la catacresis puede ser considerada un cuasi-tropo: es una metáfora obligada. Las patas de la mesa o los brazos del sillón son metafóricos, pero la metáfora no es estricta ya que carece de término literal por el cual reemplazarse. Cada

\footnotetext{
8 “Ciertamente, los relatos recurren a numerosas metáforas animales, pero para desintegrarlas rápidamente” (Yelin, 2010, p. 268).
} 
fábula de Mundo animal encadena imágenes que pretenden ceñir algo de la experiencia para la cual no hay propiamente palabras: el título del libro no debe entenderse en el sentido obvio de un cuestionamiento moral del mundo humano, sino de aquello que en la experiencia del mundo se sustrae a lo humano y puede nombrarse como lo animal. El animal es una catacresis en el título porque nombra algo de la experiencia humana de modo figurado, pero eso que nombra carece de término literal, porque apunta a una dimensión de la realidad que excede lo humano.

Lo metonímico, por su parte, disuelve el encadenamiento de metáforas en un devenir contagioso: lo simbólico se derrama en lo real, lo significante se vuelve catacresis, marca la materialidad de los cuerpos, los somete volviendo real lo simbólico, en un paso de lo inteligible a lo sensible, de lo ideal a lo material (Yelin, 2010, p. 267). En "Las poderosas improbabilidades", el lugar común verbal puede encontrarse casi al final del relato: el narrador concibe su deseo por Nora como posibilidad de ser su "sostén" (74). Es una idea estereotipada sobre la pareja: uno es el "apoyo" del otro. En el final del relato, esa fantasía se muestra ya como una "improbabilidad" (la que da el título al cuento). La metáfora se destruye cada vez en una serie de contagios metonímicos a través de los cuales se encadena la historia: la expectativa del narrador, que en ese día de campo después de la fiesta sufre la picadura de un tábano, la cual le causará una infección, su posterior convalecencia y renguera; la visión, después del episodio del tábano, de una pavita con una sola pierna entre los animales del corral, que además recuerda al protagonista otra pavita tullida de su infancia; la comprobación (¿̇o imaginación?; ¿fantasía agresiva compensatoria?) de que Nora tiene solo un pecho, cuando la amada va a visitarlo con el rival durante la convalecencia, comprobando así que ha sido derrotado en la disputa amorosa. Las tres metamorfosis de la metáfora en sentidos literales (renguera, tullidez, ablación del pecho), lo que psicoanalíticamente se puede pensar como "puesta en síntoma” (parálisis histérica del narrador, castración de Nora), actúan directamente sobre los cuerpos (humanos, animales) de modo contagioso, sensible, material. El significado se vuelve afecto, pathos.

En "Amigo enemigo", el narrador cuenta la historia de su padre: se suicidó cuando él tenía diecinueve años y estaba enamorado. Descubrirlo colgado de la ducha le provocó una mudez definitiva, que todavía padece en la adultez (de nuevo el tema del habla, de la boca y del aparato fonador). 
Arrastra, de pensión en pensión (espacio privilegiado de los personajes de ciudad en esta narrativa: desarraigo, miseria, marginalidad), una cajas con libros de química, inútil herencia paterna, cuyo fin era falsificar vinos y licores (el padre era una especie de estafador). El animal de este cuento es un pericote que vive entre las cajas y comienza a roer los libros de química. Para evitarlo, el narrador lo alimenta con migas de pan. Poco después, recibe una carta de la hermana, de la que no sabe nada hace años: siente, entonces, que no está solo (de nuevo, la nostalgia de la armonía familiar). Con el asunto de la carta, olvida al pericote algunos días y cuando está escribiendo la respuesta, el roedor sale de los libros: el papel y el pan lo han cebado, convirtiéndolo en un ser horrible, en un monstruo. Se lanza sobre el narrador, amenazante. Para defenderse, éste le clava la lapicera en el lomo y, asqueado, se desmaya, pero antes siente que recupera la voz, en forma de silbido parecido a una flauta (45-48).

Elementos kafkianos: el roedor, el episodio de la lapicera (en La metamorfosis, a Gregorio le incrustan una manzana en la espalda, que le causa a la larga la muerte), la ambivalencia respecto de la figura paterna, el repliegue del escritor, la nostalgia (también ambivalente) de armonía familiar. Pero hay otro más sutil, que retoma el problema de la voz y de la dicción, del sonido animal y de la música. El cuento intercala una referencia a la leyenda del flautista de Hamelin (el narrador escucha la leyenda y no recuerda si el nombre es "Hamelin" o "Hameln", especie de fallido que alude a Hamlet, es decir, al tema paterno): el pericote deviene múltiple de ratas. El narrador fantasea con que su mascota tenga una pareja y críen un ejército de roedores con los cuales aniquilar la ciudad. Nótese cómo en los tres cuentos analizados se pasa del animal único (narcisista-especular) al par (edípico), del par al núcleo familiar (neurótico) y de éste al múltiple, ya fuera del régimen simbólico psicoanalítico: múltiple esquizoide, animales que se derraman en lo real' ${ }^{\text {. El }}$. protagonista, mudo por culpa del

\footnotetext{
${ }^{9}$ En "Salvada pureza", el gatito del narrador, al que considera su hijo, se desterritorializa dejando el hogar y yendo a los techos, en busca de gatas hembras. Pero muy pronto es nuevamente reterritorializado por la familia que forma con una gata celosa y sus cachorros. El narrador lo sueña, sin embargo, desterritorializado, por vía de la metamorfosis, como leopardo. Los animales domésticos (el gato, el perro), los más recuperables para la unidad molar familiar, o bien se multiplican en descendencia que abandona el hogar ("Mariposas de Koch", "Nido en los huesos"), o bien devienen otros animales no domésticos (la mosca de "Es superable", los gatos de "Volamos" y de "Salvada pureza"). Por lo demás, abundan
} 
padre, proyecta su odio en el pericote, soporte ambivalente (lo cría como a un hijo, pero el animal, perdido entre los libros, es también un supletorio del padre). A partir de la leyenda y de la ensoñación, el narrador asocia la música con el chillido animal y con la posibilidad de articular la voz (48). Más elíptica, podría considerarse la alusión a "Josefina o el pueblo de los ratones” de Kafka. El chillido de la cantante, que concentra la expresión de un pueblo que ha olvidado la música, puede interpretarse como eso que está en el origen de todo arte: su pulsión mimética, lo no artístico del arte que la vanguardia pensó como arcaico pero, también, como porvenir, lo que disuelve su especificidad y su autonomía. La voz (perdida), la flauta (la música instrumental), el chillido, el aliento: cuando el narrador clava la lapicera en el cuerpo del monstruo (fantasía parricida pero también deseo desterritorializante de escritura: la "tinta roja", la presumible tendencia del protagonista a la literatura; con la sangre del padre, el narrador podrá escribir), recupera algo que no sabe si es una voz, un aliento, un canto o el sonido de un instrumento: una voz inhumana como la de Josefina, un sonido chirriante, que no es cadencioso ni termina en armonía, una disonancia.

Pero ¿̇dónde está la enseñanza moral de la fábula? El narrador junta las migas de pan para el pericote en cada comida de la pensión. La dueña lo interroga y, para justificarse, dice que son para "su hijo". Otro día la señora le pregunta cuántos años tiene su hijo. El narrador, desconcertado, no sabe qué contestar y la mujer, sin esperar respuesta, pregunta también el nombre. El protagonista escucha en ese momento a otro pensionista (el que contaba de Hamelin) hablar de las guerras y ensaya una broma: su hijo se llama Guerra. Ante la risa de la dueña, agrega: "Tiene los años de la humanidad y todavía más” (47). Ya tenemos la metáfora: el pericote simboliza la Guerra (un animal que se alimenta del hombre hasta volverse monstruo). Esta clave nos lleva de la fábula a la alegoría, en el sentido medieval y kafkiano de la palabra. Cada cuento se puede interpretar como una alegoría: la Enfermedad, la Guerra, la Culpa, el Cinismo (el gato-perro volador de "Volamos"), la Ingenuidad (Fuci, el gato de "Salvada pureza"), la Pobreza

en estos cuentos los múltiples, máximo grado de desterritorialización animal: la camada de roedores ("Amigo enemigo", "En rojo de culpa"), la bandada ("Nido en los huesos"), los hormigueros ("Sospechas de perfección"), las polillas ("Bizcocho para polillas"), la piara ("La comida de los cerdos"). 
("Bizcocho para polillas"). La alegoría se afirma, como la fábula, en un lugar común discursivo: la guerra es tan antigua como el hombre. La guerra se alimenta de los sentimientos negativos del ser humano: el odio, la culpa, el miedo, el dolor, la venganza. Como en Kafka, la fábula-alegoría funciona suspendiendo sentidos, tentando con claves "fuertes" (religiosas, políticas, filosóficas) cada vez defraudadas ${ }^{10}$.

Quizás el relato más alegórico sea "Rojo de culpa". El narrador, Abel, llamado irónicamente Caín, trabaja como "culpa paga" de los ratones (no se sabe si de una camada particular o de la especie: o, quizás, la camada representa extensivamente la especie). La reflexión moral apunta al límite lábil entre culpa y responsabilidad: "Entienden que su vida es así por culpa de los hombres, más poderosos, más numerosos, mejor armados. Cuando los ofenden, cuando los dañan, fue el hombre; cuando infestan una ciudad, la culpa es de la ciudad" (66). Una clave interpretativa puede proporcionarla la inversión: los ratones son los hombres y lo hombres los ratones. El hecho de que el ratón tenga "mala fama", sea el chivo expiatorio de males humanos (la peste, la contaminación, la enfermedad), como un mito más allá de las razones científicas, es aquí invertido: los hombres tienen la culpa cuando algo les pasa a los ratones. En este cuento, ese papel lo cumple concretamente el narrador, cuya profesión es encarnarla literalmente. El lugar común se expresa con un matiz irónico inédito hasta ahora:

El ilustrado profesor diría que no es posible destruirla, que las culpas permanecen y nos sobreviven, que moralmente solo ponemos contra ellas un acto bueno y compensador referido a la misma cuestión, aunque no ha de extinguirlas de ninguna manera (68).

Si seguimos el camino de la inversión, que opera en el sentido alegórico (en la alegoría medieval, de lo que se trata es justamente de una inversión:

${ }^{10}$ Coincidimos en términos generales con la lectura de Yelin. Sin embargo, ella no parece percibir la conexión entre los dos procedimientos: la literalización de la metáfora y la metamorfosis metonímica. Después de analizar el primero en los cuentos "Amigo enemigo" y "Bizcocho para polillas", afirma: "En otros relatos el procedimiento consiste en tratar las figuraciones animales de modo metonímico" (267). De este modo, fracciona el corpus y no percibe la relación estrecha entre ambos procedimientos: la destrucción de la metáfora que encierra el lugar común verbal es correlativa de la metamorfosis material que opera el proceso metonímico. Los dos procedimientos trabajan juntos. 
el mundo terreno figura el mundo ultraterreno, lo sensible figura lo inteligible), de modo que el Pueblo de los Ratones sea el Reino de los Hombres, encontramos hacia el final el proceso de volver la metáfora literal, operando catacréticamente sobre el cuerpo: el ser humano termina "devorado por la culpa". La camada de ratones muere arrojándose en la boca de Abel, penetrando en su interior, lastimando sus labios y utilizando su garganta de madriguera. Pero la Culpa sobrevive, como lo decía la frase citada más arriba, agonizante.

La alegoría admite un matiz suplementario: el religioso. Es una clave que ha sido aplicada a la obra de Kafka. La crítica la ha utilizado también para leer Mundo animal (Castellino, 1995). "Es superable", uno de los relatos más extraños del volumen, puede leerse como una corrosiva crítica de lo religioso, que arrastra la mirada humanista y metafísica. El narrador es un ternero que cuenta su infancia feliz en el campo y su interrupción cuando lo sacrifican para convertirlo en alimento. Pero después del episodio se convierte, cuando es transportado como carne de matadero, en un hombre que es llevado en un camión celular, preso. Como hombre, es depositado en la caja fuerte de un juez, a esperar su condena, por un crimen que desconoce (por supuesto, estamos en El proceso de Kafka, solo que en un ambiente argentino: el campo, la res, el matadero). Los conserjes, que le dan el desayuno, se quejan de su vida rutinaria y anhelan un retiro campestre. Después, un incendio destruye el edificio y la caja fuerte, convertida en horno por las llamas, convierte al hombre en un pan. Perdido en las calles después de la apertura de la caja, lo recoge un niño pobre y lo come en partes, hasta que un mendigo adulto se lo quita. Finalmente, el narrador se convierte en migas que esperan subir al cielo gracias a los pájaros. El cuento termina con esta última línea: "Yo acepto. La vida es superable" (57).

El cuento puede ser una versión de la historia de Jesucristo. Pero es, también, la historia de la experiencia sagrada del hombre que se institucionaliza perdiéndose a sí misma. Los tres estados del narrador aluden a los Evangelios: el cordero sacrificado, el hombre escarnecido y vituperado, el pan consagrado. Sin embargo, el cuento deja entrever una idea no de trascendencia del alma, sino de metempsicosis. Lo que pasa de ternero a hombre y de hombre a pan es la conciencia: no hay "muerte" entre un paso y otro o, mejor dicho, la muerte no le acontece a la conciencia que pasa de un estado a otro, solo al organismo físico. El protagonista ha superado, dicen 
los conserjes, "la materialidad constante" (54): ha cambiado de materia, su alma ha pasado de una a otra. La metempsicosis niega que haya un más allá de la materialidad mundana. Pero también descarta el materialismo craso: "Y no puedo entender si la angustia me viene de pensar o es que hace falta la angustia para poder pensar" (53). El texto se reapropia de una clave existencialista, circulante en Argentina en los años cincuenta: la angustia es el sentimiento de pensar la propia existencia como fundamentada en la nada. No puede, sin embargo, cerrarse la lectura del texto con esta clave, ni con ninguna otra. El relato trasunta una nostalgia por la experiencia sagrada: el niño pobre que recoge el pan consagra un pedazo antes de comerlo, a pesar del hambre. El narrador considera que "es un rito infantil o campesino o de los pobres" (56). El episodio, en el final del relato, no es una redundancia que subraya la clave bíblica: es un elogio de la experiencia sagrada, justo cuando el relato podría cerrarse en una clave antirreligiosa, existencialista o atea, materialista crasa. El pobre, el niño, el campesino, el inocente, el tonto, el animal: personajes dibenedettianos que pueblan los cuentos, sujetos de experiencias que se sustraen a la racionalización adulta, dominadora y represora de lo sensitivo, lo corporal, lo material, lo inmanente, lo sagrado.

Por su parte, el problema de la corporalidad está en estrecha conexión con la animalidad, la percepción no categorizada de la materia informe, lo sensitivo. El narrador es en cada relato un cuerpo sujeto a pathos: enfermedad, erotismo, desmembramiento, sufrimiento. Merece interrogarse, sobre todo, la recurrencia del tema del despedazamiento. Es un tópico que se presta muy bien al abordaje en clave negativo-existencialista o psicoanalítica ${ }^{11}$. Es como la enfermedad en Kafka: motivo apto para interpretar la relación conflictiva del checo con el cuerpo, la sexualidad, el matrimonio. Deleuze y Guattari han polemizado con esta lectura: la enfermedad es en Kafka una potencia, una posibilidad. La carencia es afirmativa: permite la sustracción del cuerpo, el escape del mundo racional y administrado que lo sujeta, la huida de la institución matrimonial (1978, pp. 63-65). No es un padecimiento, es una "salida" (recordemos el cuento "Las poderosas improbabilidades": lo improbable es un poder). En Mundo animal, enferme-

${ }^{11}$ Cfr. (Varela, 2007): el cuerpo de Mundo animal es, en esta lectura, siempre metafórico y los avatares que padece (enfermedad, corrosión, destrucción), siempre negativos. 
dad, fantasía de desmembramiento, transformación animal, son ejercicios de ascesis extremos (como en el cuento de Kafka "El artista del hambre"). En el caso del deseo de desmembramiento (recuperable por la clave simbólica del masoquismo), hay que señalar, contra la lectura negativa, que no es el horror o la angustia ante el peligro de disolución subjetiva lo que figuran estos relatos, sino más bien su tentación, su horizonte de libertad: una tentativa de éxtasis, de borradura del propio ser en la materialidad indiferenciada de lo vivo ${ }^{12}$. Como lo veíamos en "Es superable", el animal existe sin pensamiento, por lo tanto sin angustia: su cuerpo es un todo con su entorno, es pura inmanencia. Lo que es superable no es la vida, como puede malinterpretarse tomando la oración en su límite natural, sino la "vida humana". El cuerpo al límite de lo vivo, destruido y descuartizado, propone una alternativa entre la vida y la muerte como experiencia de no poder morir. El tuberculoso de "Mariposas de Koch" agoniza mientras las mariposas salen de su cuerpo. El narrador de "Amigo enemigo" se desvanece de asco, pero sobrevive y recupera el habla. El protagonista de "Nido en los huesos" pide que alguien azuce a los perros para morir como el mono. El de "Es superable" llega hasta las migas de pan que se doran al sol y espera la "muerte alada" de los pájaros. El de "En rojo de culpa" agoniza y contempla cómo las pulgas abandonan a los ratones muertos y se abalanzan sobre su carne caliente. En "Bizcocho para polillas", el narrador, que no puede ponerse ninguna ropa sin que las polillas lo dejen cada vez en harapos, termina por sucumbir ante ellas y, con una triquiñuela, logra que se coman una parte de su corazón mientras la restante palpita de agradecimiento.

La fantasía de destrucción del propio cuerpo es un operador de lo que Deleuze y Guattari llaman la imaginación molecular del esquizofrénico: el despedazamiento es la transformación del organismo (es decir, la organi-

${ }^{12}$ Esta imposibilidad de leer la potencia de lo destructivo o negativo en los relatos de $\mathrm{Di}$ Benedetto lleva a la crítica a tratar de justificar la ambivalencia de los animales, que oscilan entre la protección y la amenaza, lo que deja la interpretación dentro de los límites del símbolo psicoanalítico (protección parental/amenaza de castración). Hay muchos ejemplos, citamos uno: "Al parecer positiva, la imagen del perro va adquiriendo perfiles más complejos, que si bien, no totalmente negativos, conllevan una sutil amenaza" (Varela, 2011, p. 284). Esta ambivalencia se plantea también en relación con la fábula, como la lucha entre el Bien y el Mal, lo que permite resolver el problema. Para nosotros, en cambio, el paso de lo protector a lo agresivo es una transformación positiva de un deseo desterritorializante que desenmascara la unidad molar de la armonía familiar: no hay ambivalencia, hay metamorfosis esquizofrénica, puesta en trabajo de lo destructivo. 
zación estructural de la vida) en "cuerpo sin órganos": una corporalidad entendida como campo de intensidades, como múltiple de moléculas sensitivas, de partículas libidinales. Por la generación y la sociedad provinciana a la que pertenecía, Di Benedetto no podía más que considerar con seriedad esas unidades molares que son lo conyugal, lo familiar, lo profesional, lo social. De ahí cierto pudor, muy en sintonía con su célebre austeridad, en la mención directa de temas que atañen a la sexualidad, los rencores en las relaciones familiares, las tendencias antisociales agresivas. Lo metafórico, en lo fantástico y lo alegórico, en la fábula y la parábola, pudieron ser una vía indirecta para canalizar una imaginación esencialmente esquizoide, perversa, corrosiva del pensamiento tranquilizador de la armonía familiar, social, cultural. Pero los relatos van mucho más lejos que las intenciones del autor: trasuntan esa disimulación metafórica en una muy eficaz máquina catacrética. La destrucción del yo corporal no es angustiosa ni culpable ni negativa: es la afirmación de una intensidad impersonal, la de lo animal como fuerza vital que desborda los límites de lo humano, las unidades molares del cuerpo, la familia y el todo social.

"Sospechas de perfección" es el relato más extraño, más extenso y más concentrado del volumen: sintetiza todos los motivos que hemos recorrido, al tiempo que resume la idea moral de la fábula en un párrafo que da título al libro. Es también el más kafkiano, sin que los intertextos sean lo más destacable (aunque los tiene: El castillo, El proceso): posee la rareza de los mejores cuentos del checo, la saturación de sentidos equívocamente alegóricos, la sensación de opresión, el onirismo que lo tiñe todo, la desorientación genérica (no se sabe si es un cuento fantástico, maravilloso, alegórico o surrealista). Un hombre, en principio extranjero (después se nos dice que nació ahí), llega a una comarca en la que las personas no saben leer ni escribir. Como quiere vender libros, comienza a impartir lecciones de lectura. Por eso motivo, es condenado, sin juicio, a muerte. El "pelotón" es literalmente una "pelota" de hormigas que comen sus carnes. Como no pueden con su esqueleto, lo dejan así, a la espera de otro pelotón especializado, que resulta ser uno de hormigas voladoras. Durante la noche, el condenado se lamenta ante las hormigas y éstas, súbitamente, le prestan atención: “-iY bien, adelante! Basta de quejidos. Soy uno de los sostenedores de este Reino de los Hombres (que apenas es algo más que un Mundo Animal). Que se cobren en mí, las bestias, lo que de ellas despreciamos, condenamos y 
tememos..." (80). Las hormigas se solidarizan y lo llevan volando hasta un país limítrofe. El protagonista encuentra ahí un paisaje de cuento de hadas: un río de leche y otro de vino. Vive entonces una nueva vida en la que recupera sus carnes: segunda infancia a la vera del río de leche y segunda madurez a la vera del río de vino. Después entra en contacto con los pobladores, cuya "sospecha de perfección" (son muy corteses y lo reciben bien en todos lados) lo hace concebir un plan bélico para atentar contra el equilibrio de ese país: destruir sus ídolos, el principal de los cuales es la música, homenajeada en la plaza principal por una fuente de luces. Este intento fracasa y el protagonista es llevado a un nuevo juicio, pero esta vez para cumplir sus deseos: quiere amor y le dan una mujer; no quiere trabajar, quiere retirarse al bosque, junto al río de leche, a pensar; este deseo no es concedido, porque los jueces opinan que corre el riesgo de "devorarse a sí mismo" (84). Le dan, entonces, un lugar en ese bosque, mujer y trabajo. Todo parece estar bien. Pero de repente el narrador, que está pensando en los ríos de leche y de vino, imagina un río de sangre. Recuerda, en un paroxismo de horror, a uno de sus jueces enmascarados en el país donde fue descarnado. Entonces se le pregunta, como en un sueño, si quiere regresar a la otra comarca. El narrador quiere decir que no, pero dice que sí. El cuento termina: “-Volverás al otro país. Nuestras huestes, con tanto amor armadas para las glorias de la victoria, acogerán con gratitud tus conocimientos del adversario y de su suelo, hombre reconstituido" (85).

A partir de la expresión sobre el Reino de los Hombres y el Mundo Animal, se pueden desentrañar una serie de símbolos: la condena de un país bárbaro por la introducción, simultánea, de la cultura y el comercio (co no se trata de un país bárbaro sino de uno que resiste a la imposición de la civilización única?); el cinismo del ser humano (el país amante de la justicia que condena sin juicio); el ansia de libertad (de nuevo ligada al tópico de los animales con alas); la guerra como respuesta de un país en la cúspide de su civilización. Pero todos esos símbolos se vuelven equívocos al entretejerse en un relato que relaja los vínculos causales, rompe la lógica (los cañonazos que anuncian la ejecución porque la misma debe realizarse "con el mayor sigilo", 78), deshilacha la historia. De nuevo, la clave del fantástico es una posibilidad, por cuanto la segunda parte puede ser un sueño del condenado: pero esta clave se vuelve también inestable porque todo el cuento es de un marcado onirismo, de modo tal que la vacilación se disuelve en 
un "sueño dentro del sueño" (lo cual vuelve la distinción sueño/realidad impertinente), como en "Las ruinas circulares" de Borges ${ }^{13}$.

La fantasía corporal es en este cuento ser descarnado, quedar "en huesos", expresión que en español rioplatense alude a la exposición afectiva y a la vulnerabilidad emocional. El personaje viaja a un país que es, de modo simultáneo, extranjero y natal: quiere integrarse, pero es rechazado, condenado, descarnado. En el país vecino, todo le es concedido. Sin embargo, primero quiere destruir la armonía social y después, cuando tiene la posibilidad de tener un hogar, quiere renunciar al trabajo (sospechamos, además, que quiere dedicarse a beber en el río de vino). Cuando le proponen un grupo de mujeres para que elija con cuál formar pareja, el narrador pregunta si puede casarse con todas, lo que por supuesto le es negado. Es decir, todos los deseos del personaje son agresivos, perversos, desterritorializantes: corroen las unidades morales de la patria (ser un extranjero en el país natal, ser un habitante del país extranjero), la sociedad (destruir la armonía, la perfección), el trabajo (vivir ociosamente al lado del río de vino), el matrimonio (deseo de poligamia). Ese impulso destructivo del narrador es reterritorializado por el segundo país que, civilizado, pretende canalizarlo hacia la invasión del vecino: la máquina perversa que corroe las unidades molares es integrada y utilizada en una máquina de guerra, disimulando su carácter político a través de una fórmula épica que sintoniza con el ambiente de leyenda y mito del relato.

En síntesis, Mundo animal propone un conjunto de fábulas kafkianas en las cuales lo animal aparece como metamorfosis de una humanidad sin humanismo, no antropocéntrica y extrañada de sí misma. No se trata de un animal metafórico sino metonímico: un devenir que conecta lo humano

${ }^{13}$ Algo similar ocurre con el cuento "Reducido". El narrador, de vida triste y fatigada, tiene un perro en sus sueños, que lo consuela de sus penurias diurnas. Pero su miedo es que el perro, una noche, no vuelva: por eso lo caracteriza con un oxímoron, "pesadilla simpática" (58), ya que su carácter de mal sueño radica en su posibilidad de desvanecimiento. Decide, entonces, proponerle a Reducido (así se llama el perro) que se vaya con él a la realidad. Pero recibe una contrapropuesta inquietante y el cuento termina cuando el narrador, explicando que tiene que contestarle esa misma noche, la expone: Reducido quiere que se vaya él a vivir a los sueños. De nuevo, la fantasía no es compensatoria: el sueño posee una potencia de la que la realidad carece. El deseo del narrador es vivir en los sueños, es decir, no hacer sus sueños realidad, sino que la realidad tenga la belleza inquietante del sueño: que sea, en suma, una pesadilla simpática. 
con lo viviente, haciendo la experiencia de aquello que la formulación de lo humano rechaza para afirmar su propia esencia. Este devenir corroe las unidades molares del cuerpo, la familia y la sociedad: es decir, todo lo que, desde el nivel individual hasta el colectivo, se establece como conjunto organizado y jerarquizado. La imaginación esquizoide dibenedettiana corroe cada una de estas organizaciones, haciendo del trabajo de negación una afirmación festiva, destructiva, perversa y polimórfica.

\section{Referencias}

Boldori, R. (1968). Di Benedetto y las zonas de contacto. En R. Barufaldi, R. Boldori y E. Castellio (eds.). Moyano-Di Benedetto-Cortázar (pp. 35-50). Santa Fe: Ed. Crítica 68 y Colmegna.

Campos, M. (1987). Simbología animal dibedenettiana (fragmento). Diario Hoy, Mendoza, 11 de octubre, sección Cultura: 3.

Castellino, M. E. (1995). Inquietud religiosa y discurso parabólico en Mundo animal de Antonio Di Benedetto. Piedra y Canto. Cuadernos del CELIM, 3, 35-53.

De Miguel, M. E. (1970). Aproximaciones a la obra de Antonio Di Benedetto. Nueva Crítica, 1, Buenos Aires.

Deleuze, G. y Guattari, F. (1978). Kafka. Por una literatura menor. México: Era.

Di Benedetto, A. (2006). Cuentos completos. Buenos Aires: Adriana Hidalgo.

Filer, M. (1980). Los animales simbólicos de Antonio Di Benedetto. En R. Minc y M. Frankenthaler (eds.), Requiem for the "boom"-premature? A Symposium (pp. 23-136) Montclair, N.J.: Montclair State College.

Maturo, G. (1987). La aventura vital en la creación de Antonio Di Benedetto. En A. Di Benedetto, Páginas de Antonio Di Benedetto seleccionadas por el autor (pp. 11-39). Buenos Aires: Celtia.

Néspolo, J. (2004). Ejercicios de pudor. Sujeto y escritura en la narrativa de Antonio Di Benedetto. Buenos Aires: Adriana Hidalgo.

Premat, J. (2009). Lo breve, lo extraño, lo ajeno. En A. Di Benedetto, Cuentos completos (pp. 5-31). Buenos Aires: Adriana Hidalgo.

Robert, M. (1963). L'Ancien et le nouveau. Paris: Bernard Grasset.

Todorov, T. (1994). Introducción a la literatura fantástica. Buenos Aires: Tiempo Contemporáneo.

Varela, F. I. (2007). Cuerpos invadidos: Cuerpo y corporalidad en algunos relatos de Antonio Di Benedetto. Revista de Literaturas Modernas, 37/38, 209-228.

. (2011). Reino de hombres, mundo animal: Presencia animal en la narra- 
tiva breve de Antonio Di Benedetto. Anales de Literatura Hispanoamericana, 40, 279-296.

Yelin, J. (2010). Kafka en Argentina. Hispanic Review, 78(2), 251-273. 